\title{
Challenges to registry-based epidemiology in post-modernistic civilization
}

\author{
Lorentz M. Irgens \\ Professor of Preventive Medicine, University of Bergen \\ Director of the Medical Birth Registry of Norway
}

Based on the opening lecture at the $1^{\text {st }}$ Nordic conference in epidemiology, Bergen, June 2000.

To account, in a proper epidemiological way, for the nation's births and deaths as well as cases of cancer has, until recently, been a hallmark of our Nordic civilization, if we can use such a term. Today, I have an increasing feeling that this is not the case any more. Unfortunately, we have seen examples in our countries that would support such a feeling.

The title represents a challenge to the lecturer, and hopefully to the audience as well: In a booming economy, in a civilization drowning in oil, in which every decision, important or trivial, is based on supply and demand viz. our contemporary post modernistic civilization, epidemiology is not necessarily needed. Prevention of illness and suffering is not an unconditional, evident good. To survive as epidemiologists we have to make people realize that our civilization shall not survive without epidemiology and preventive medicine. To be more pragmatic and to use the terminology of our contemporary civilization: we have to make the community willing to pay for our services. I shall return to this challenge in a short while.

\section{WHY REGISTRY-BASED EPIDEMIOLOGY?}

Future epidemiology may follow two strategical pathways of particular interest: registry-based epidemiology and genetic epidemiology. These pathways were identified at the meeting of the International Epidemiological Association in Copenhagen in 1994. Particularly, D. Trichopoulos uttered a strong belief in what he called megaepidemiology based on registries. Since then, the potential of these two pathways has increased considerably. However, there is no reason to believe that the two shall never meet. Rather, it is the merging of these pathways that will define future epidemiology.

Registry-based epidemiology represents a framework that enhances enormously the potential of genetic epidemiology. And why registry-based? For three main reasons:

- it provides large numbers with power to assess not only main effects, but also effect modification

- it represents data that already exist, in many cases reported for other purposes which may add to data quality and represent a cost-effective approach
- it is a prerequisite for epidemiological surveillance for which there will be an increasing need in the future.

However, before dealing in more detail with registrybased epidemiology, I would like to say a few words about the main challenge in our time to epidemiology in general. And I would like to add that this lecture should not be considered a paranoiac, pessimistic cold shower, but rather a reminder or warning in a society in which I believe there is still a true search for humanistic values.

The main challenge is related to the fact that epidemiologists all over the world may be considered a religious, perhaps closed, congregation, in which there is a consensus about the objectives - namely to acquire knowledge about causes of diseases in order to prevent. To my surprise, in our post-modernistic civilization, the positive aspects of this knowledge are doubted by the general public.

\section{FEAR OF KNOWLEDGE AND OF LOSING INTEGRITY}

A year ago, I took part in a discussion with the director of the Data Inspectorate of Norway, a former conservative member of parliament, Georg Apenes, who asked whether this knowledge of risk factors might affect the integrity, the independence and the wellbeing of man. This question may relate to basic postmodernistic values in which the roles of the community in general and especially public health are seriously questioned. Each individual knows what is to the best for him or herself.

On quite different grounds, our objective, to acquire knowledge in order to prevent, is attacked by economists. They claim, to an increasing extent, that preservation of life beyond post-productive ages, i.e. after retirement, is too expensive for the community; truly a civilization based on supply and demand! These examples illustrate various aspects of the challenge we are facing.

Particularly, the former, representing the fear of knowledge and, on these grounds, questioning the objectives of epidemiology, needs a discourse. Apparently, these thoughts are prevalent in our post-modernistic 
era, but are they truly novel? Similar thoughts may be identified in perhaps the most important root of western civilization, the Bible. In Genesis, the Lord God said to Adam: "of the tree of knowledge of good and evil, thou shalt not eat: for on the day that thou eatest thereof, thou shalt surely die". We all know the act of the serpent and what later happened. The tree of knowledge of good and evil and the eating of its fruit have called for a multitude of incompatible explanatory attempts (1). The act of eating has been alluded to as getting sexual experience on the one extreme and as just disobedience to the Lord on the other. However, it seems reasonable to infer that the more general understanding, that acquisition of knowledge or omniscience per se is a mortal sin, has represented an influential and widespread interpretation of the legend.

This attitude to knowledge is perhaps what we witness in our post-modernistic civilization. In my opinion, we may come to terms with this paradox if we introduce the double serpent of Asclipios in which the one, according to tradition, represents knowledge and the other wisdom. Since antiquity, medicine has used the twined snakes as a symbol, implying that knowledge should not be applied without wisdom. For example, a risk factor identified in one epidemiological study should not, without further evidence on its validity, as well as feasibility and consequences of relevant preventive measures, be introduced in recommendations to the public. Subsequently, the effects of the eventual recommendations should be subject to epidemiological surveillance. Unfortunately, this has not always been the case.

A complex closely linked with fear of knowledge is the inherent feeling of guilt or aggression among victims of the illness or their relatives. They may be people without the necessary knowledge, or even worse, knowledgeable people without the adequate behaviour. We may truly cause unhappiness when we confront people with a high-power risk factor to which a high number of cases might be attributed. The issue has i.a. been raised after the detection of the very strong association between the prone sleeping position and sudden infant death syndrome. Still, we feel that concealing such information from the public is unethical, and in this example, we believe that most people agree.

Thus, even if we work against odds rooted in the antiquity as well as in contemporary public debate, I guess that the general public may still be convinced of our objectives - the "why" in epidemiology, that data collection and analysis are tools necessary for the prevention of illness.

The next challenge deals with the "how". Data collection on individuals in general is met with scepticism and particularly data collection for registries. This problem is also deeply rooted in history and even in the same source that we have already dealt with.

"And it came to pass in those days that there went out a decree from Caesar Augustus that all the world should be taxed." Apparently the English translation is more frank and honest than our Nordic, which states: "that all the world should be registered in a census". And maybe the English translation gives a clue to the public animosity. However, even if this was the first census in Cyrenius' time, it was not the first in history. Around 1000 B.C.., King David made a census of his people, not for taxation but for military aims. The Lord informed David that he had sinned, so for this reason, the census is referred to as one of the great sins of the Old Testament, actually without, to any extent, specifying why (2). Its great impact on subsequent generations is illustrated in a painting from the $16^{\text {th }}$ century (Figure 1), depicting the Lord's punishment on King David in terms of a pestilence lasting 3 days. Thus, even in the question of "how", we have odds against us rooted in antiquity. Possibly, the fear of losing integrity is related to the same source.

\section{THE EVOLUTION OF REGISTRY-BASED EPIDEMIOLOGY}

Admittedly, the epidemiology of acute diseases with no long-term implications would not benefit from a registry. According to the WHO's definition, a register is a collection of permanent records on individuals with the intention of long-term follow-up (3). Challenged foremost by acute epidemics, the Middle Ages and the Renaissance never saw the development of disease registries. There would also have been obvious logistic limitations.

The first national disease register ever to have been established actually evolved in Bergen in the shadow of Snow's pioneer cholera studies in london. In 1856, by a royal decree, Ove Guldberg Høegh established the National Leprosy Registry of Norway (4). Interestingly, the leprosy problem in Norway was also first addressed by separate patient censuses, in 1836, 1845 and 1852 . The censuses revealed a low case ascertainment, but still increasing numbers, and finally, the disease seemed to approach the capital. The need for a registry was urgent.

The registry came to serve three different objectives:

- to assess secular and geographical trends, i.e. epidemiological surveillance

- to, at any time, assess total needs for care, e.g. in terms of number of hospital beds, and administer individual follow-up of each patient, i.e. health services quality assurance

- and finally, to clarify the etiology of the disease, including genetic aspects, i.e. epidemiological research.

Already in 1858, Høegh stated that the Leprosy Registry was the means by which etiological clarification should be attained. Through the years, more than 8,000 patients were registered, and the registry was instrumental in achieving all the targets specified. 


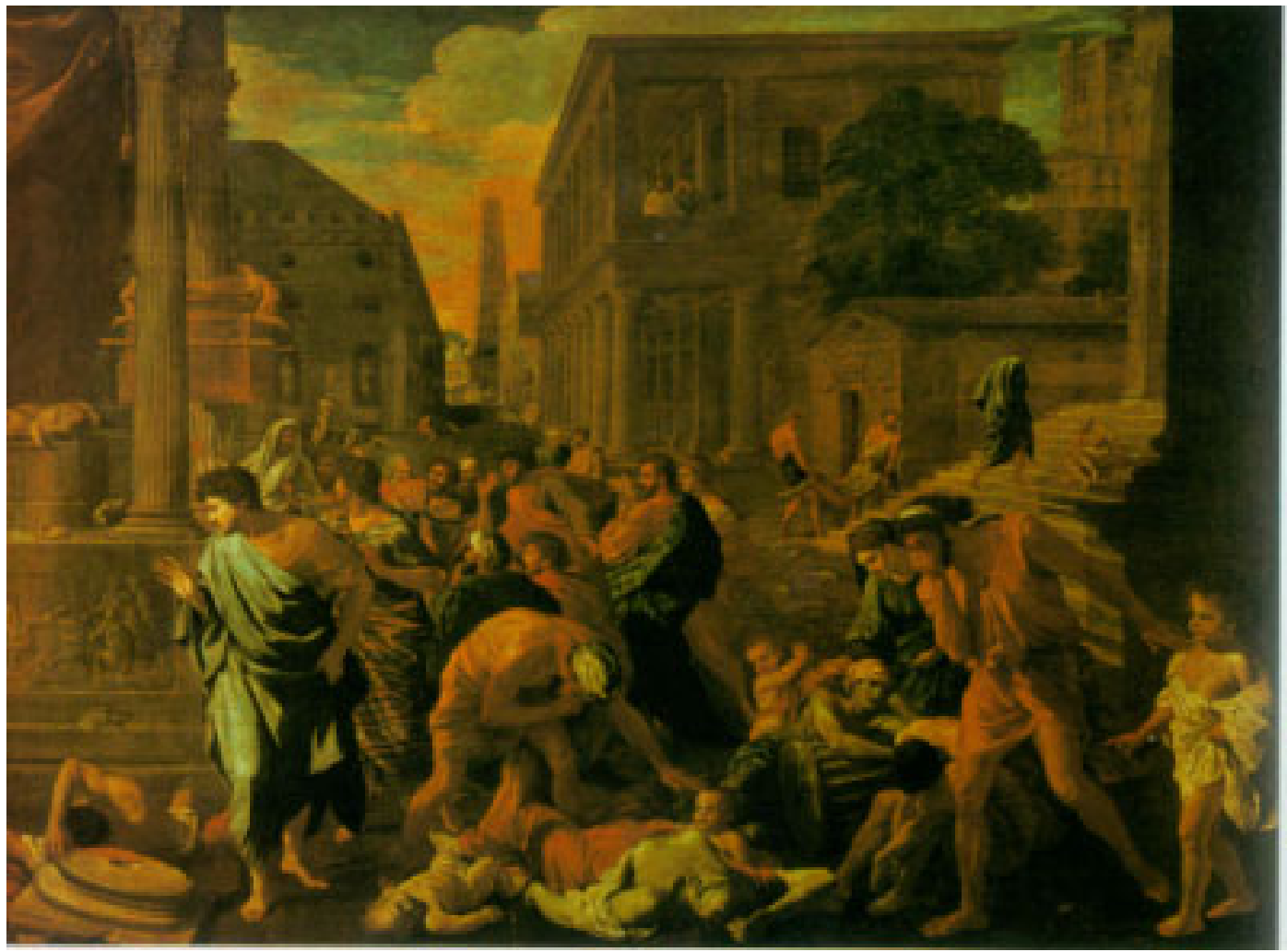

Figure 1. Nicolas Poussin: The Lord's punishment on King David, in terms of a pestilence, for having made a census of his people.

A computerized version of the registry has, during the last 20 years, been utilized to shed light on the epidemiology of declining leprosy (5). Its broad implications may be illustrated by a Dutch validation study of a computer simulation programme for modelling the transmission and control of leprosy (6). Last year, this programme was validated against the National Leprosy Registry of Norway.

During the next 100 years, the Nordic countries saw the development of epidemiological registries for causes of death, for tuberculosis and for cancer (7). All these registries represented registration by indication, i.e. either a disease or death.

Even if a cause of death registry eventually receives data on the total population, a new milestone was passed when the medical birth registries were established around 30 years ago, the first one in Norway in 1967, with data for both numerators and denominators (8). In contrast to previous registration, these registries were provided with data not only on outcome variables, but also on exposure such as medical history before and during pregnancy, as well as obstetrical complications. Since 1999 onwards, data on maternal smoking, medication, vitamin supplementation and occupation have also been available.

The statutes of the Medical Birth Registry of Norway indicate the needs for information expressed by the community at the establishment of the registry:
- To clarify causes aiming at prevention

- To run epidemiological surveillance of perinatal health problems

- To run quality assurance of health services

- To develop norms, standards and recommendations

The Nordic medical birth registries, the cancer registries and the cause of death registries represent the core of what might be considered Nordic registrybased epidemiology.

\section{CHARACTERISTICS OF NORDIC POPULATION-BASED REGISTRIES}

The Nordic population-based registries all use the national identification number system for all data notified and registered. In Norway, the Data Inspectorate has questioned the need for identifying permanently the records of the health registries. Both the Cancer Registry and the Medical Birth Registry have provided lists of vital arguments demonstrating the urgent necessity of permanent identification, both for epidemiological research and surveillance purposes.

They are all national registries covering a specified area, and thus population-based. In our time, a wind of decentralization is blowing, which evidently represents a challenge or, to be quite frank, a threat to the national epidemiological registries. Decentralization reduces standardization and thus comparability, it reduces 
the total material and it dilutes and weakens the scientific competence in that field of research. And above all, it represents a threat to the stability and continuity of a national system.

At the moment, a proposed Bill on Health registries is in the Parliament waiting to be passed. The bill introduces informed consent to registration as a leading principle. However, regulations to the Act will be prepared for each register in which compulsory notification may be authorized, if considered justified. Both the Cancer Registry and the Medical Birth Registry have issued to the Ministry of Health strong arguments in favour of compulsory notification.

These registries improve data quality in interactive communication with the notifyer, for example by increasing ascertainment of birth defects among all births notified. Case ascertainment may also be increased by record linkage, in our example with the Cause of Death Registry and the register of abortions induced after 12 weeks gestation.

Furthermore, a classical problem of doublet records is eliminated by internal record linkage. Even recently, this problem has amply been demonstrated in a registration system not based on identification of the individual. In Norway, the Central Bureau of Statistics has operated a registration of induced abortions based on notifications without personal identification. During the last year, a parallel system based on personal identification has been run by the Medical Birth Registry by which a considerable number of doublet records has been identified.

Finally, the Nordic epidemiological registries represent institutions per se, they are registries or systems of ongoing registration, not only collections of data represented by a register. This characteristic varies between the Nordic countries, and is probably most pronounced in Norway. As far as the medical birth registries are concerned, Denmark seems to have preferred a low- profile organizational model, while Sweden and Finland have chosen a model in which the medical birth registries have an individual identity, but are still integrated with other epidemiological registries. In Norway, the Medical Birth Registry and the Cancer Registry are separate institutions with a strong internal institutional identity and with a distinct external profile. Admittedly, I represent the latter organizational model, and I see the advantages in terms of a strong team identification in both the scientific and clerical staff. I also see the advantage in terms of a high-profile professional centre for the health problems involved, which the community at large can address when the needs arise.

\section{FUTURE NEEDS FOR EPIDEMIOLOGICAL REGISTRIES}

Why does future civilization need these registries? Or to put it another way - why cannot future epidemiology be based on ad hoc data collection? I will try to answer the question by identifying important aims of our epidemiological registries addressing both research and surveillance aspects.

In epidemiological research long-term follow up is impossible or maybe unfeasible without registry data. Hypotheses that adult disease is programmed in utero or soon after birth have been difficult to test due to lack of adequate data. In the years to come, the potential to clarify the issue on the basis of registry data is certainly enormous. There is also a need for more well-established follow-up research in terms of assessing the effects of various perinatal factors on future disability. Co-operation between cancer registries and medical birth registries with data on exposure and outcome has already been established. An example is pregnancy outcome in childhood cancer survivors.

The epidemiological registries enable us to study outcome in family structures either established by the registry itself (medical birth registries) or in structures provided by external sources (general population registries) with record linkage (cancer registries). The potential of adding data on candidate genes to these studies will no doubt represent a major breakthrough in epidemiological research.

Social inequality represents another challenge to registry-based epidemiology. To me, it seems unacceptable that in egalitarian Norway, a relative risk of 2.6 is observed for perinatal death among children of fathers with elementary school versus children of fathers with a university degree (9). For our epidemiological registries, record linkage with external sources of data on social variables should be further exploited.

In epidemiological surveillance, the threats to our environment from pollution represent an increasing challenge to the registries. In principle, the cancer registries and the medical birth registries meet identical problems even in terms of potential agents since many carcinogens are teratogens and vice versa. The major difference is the period of latency; several decades versus 9 months. In general, such surveillance has to be registry based due to the need for expected or baseline values. The following 4 scenarios are relevant:

(1) Routine, ongoing epidemiological surveillance in which prompt detection of a deviation from a baseline is intended.

(2) Ad hoc investigation of a possible cluster detected for example by the health services or the public. The Medical Birth Registry of Norway has been involved in a series of such clusters, e.g. 4 cases of anophthalmia in Finnmark which turned out to represent a genetic cluster, 11 cases of limb reduction defects in a Nordland municipality which is still under genetic investigation, 3 cases of club foot in infants of fathers serving onboard a Navy motor-torpedo boat, which is still under investigation, and 5 cases of Down syndrome in a former elementary school class which turned out to represent a random event. Similar examples are abundant in the cancer registries as well.

(3) Ad hoc investigation of suspected exposure. 
Here, the major example is the post-Chernobyl surveillance in Norway. In a co-operation with the Norwegian Radiation Protection Agency providing municipality- and month-specific doses of air- and foodborne radiation, we were able to undertake an exposure-specific surveillance (10). This methodology should be applied when a similar scenario becomes relevant in the future. Once again I want to stress that such surveillance is dependent not only on an ongoing system for collection of cases, but also for calculation of baselines. In the future, exposure-specific surveillance might be based on information on occupation either collected by the registries themselves or provided by record linkage. Here, I would like to include the possibility of surveillance of exposure. This has been brought up after the identification of prone sleeping position as a strong (RR14) (11) and prevalent (50\%) (12) risk factor for SIDS, which might justify a surveillance of infant care practices. Surveys of smoking habits is an example of surveillance of exposure with long traditions. However, such a surveillance does not need a registry as its basis.

(4) Quality assurance within the health services defines a function close to epidemiological surveillance. The hospitals of our time represent enormous community investments, but still signs and symptoms of crisis are evident, at least in our country. Thus, there is an increasing need to assess the extent to which hospital services are sufficiently and adequately provided to citizens in all parts of the country, for which end our epidemiological registries are instrumental.

\section{CONCLUSIONS AND IMPLICATIONS}

In conclusion, the hallmark of our Nordic epidemiological registries is their involvement not only in research, but also, by epidemiological surveillance, in public health management and operation. This dual function is mutually fertilizing. The great scientific potentials of epidemiological registries have been appreciated by the University of Bergen. In 1998, the Medical Faculty authorized with separate funding a Locus of Registry-Based Epidemiology as an officiallyrecognized research group with the Medical Birth Registry as its core activity, and including another 5 national or regional registries, among which the National Arthtroplasty Registry represents a pioneer quality assurance registry.

I foresee future threats to our organizations. A main objective is to demonstrate the urgent needs for epidemiology in our post-modernistic civilization. If we succeed, what remains is fairly easy - the registries represent the most inexpensive way to meet the multitude of needs accounted for. The alternative, to establish ad hoc studies when the needs arise, perhaps with low participation rates, is not only extremely expensive, but also time consuming; the answers will have to be deferred to a distant future. By having adopted this way of arguing from our oil-ridden, immediateresults-influenced economy, I conclude that the circle is closed, and I feel no fear faced with the future challenges addressed to registry-based epidemiology in a post-modernistic civilization.

\section{REFERENCES}

1. Michelsen LM. Fortolkning til 1. Mosebok (In Bibelverket). Oslo 1972.

2. Hauge D. Fortolkning til Samuelsbøkene (In Bibelverket). Oslo 1973.

3. Who Expert Committee on Health Statistics: Epidemiological methods in the study of chronic diseases. Wld Htlh Org Techn Rep Ser No 365. Geneva 1967.

4. Irgens LM, Bjerkedal T. Epidemiology of leprosy in Norway: the history of the National Leprosy Registry of Norway from 1856 until today. Int J Epidemiol 1973; 2: 81-89.

5 Irgens LM. Leprosy in Norway. An epidemiological study based on a national patient registry. Leprosy Rev 1980; 51 suppl.1: 1-130.

6. Meima A, Gupte MD, Van Oortmarssen GJ, Habbema JD. Trends in leprosy case detection rates. Int $J$ Leprosy 1997; 65: 305-319.

7. Irgens LM, Bjerkedal T. Utviklingen av informasjonssystemer i helsesektoren og bruken av disse $\mathrm{i}$ det forebyggende helsearbeid. Tidsskr Nor Lageforen 1976; 96: 295-300.

8. Irgens LM. The Medical Birth Registry of Norway. Epidemiological research and surveillance throughout 30 years. Acta Obstet Gynecol Scand 2000; 79: 435-39.

9. Irgens Å, Krüger K, Skorve AH, Irgens LM. Yrke og reproduksjonsutfall. Medical Birth Registry of Norway. Technical reports, I, 1996: 1-105.

10. Irgens LM, Lie RT, Ulstein M, Skare Jensen T, Skjærven R, Sivertsen E, Reitan JEB, Strand P, Strand T, Skjeldestad FE. Pregnancy outcome in Norway after Chernobyl. Biomed Pharmacol 1991; 45: 233-241.

11. Øyen N, Markestad T, Skjærven R, Irgens LM, Helweg Larsen K, Alm B, Norvenius G, Wennergren G. Combined effects of sleeping position and prenatal risk factors in sudden infant death syndrome. The Nordic Epidemiological SIDS Study. Pediatrics 1997; 100 (4): 613-621.

12. Irgens LM, Markestad T, Baste V, Schreuder P, Skjærven R, Øyen N. Sleeping position and SIDS in Norway 1967-91. Arch Dis Child 1995 72: 478-82. 
